\title{
Perforation due to Lead
}

National Cancer Institute

\section{Source}

National Cancer Institute. Perforation due to Lead. NCI Thesaurus. Code C101246.

Penetration of a lead through a systemic vein, coronary vein, or the myocardium. (ACC) 